\title{
The NR1 subunit of the $N$-methyl-D-aspartate receptor can be efficiently expressed alone in the cell surface of mammalian cells and is required for the transport of the NR2A subunit
}

\author{
Mónica GARCÍA-GALLO, Jaime RENART ${ }^{1}$ and Margarita DÍAZ-GUERRA \\ Instituto de Investigaciones Biomédicas 'Alberto Sols' CSIC-UAM, Arturo Duperier 4, 28029 Madrid, Spain
}

\begin{abstract}
We have used a heterologous system of expression of $N$-methylD-aspartate (NMDA) receptors based on the use of vaccinia virus to analyse the maturation, transport, assembly and differential expression of the NR1 and NR2A subunits of the receptors. We have demonstrated that the NR1 subunit is efficiently transported to the plasma membrane in cells expressing NR1 alone, similarly to cells producing NR1 and NR2A together. In contrast, NR2A requires NR1 expression to be located at the cell surface. The stability of both receptor subunits expressed alone is similar to that obtained in cells producing NR1 and NR2A. In pulse-chase experiments, the NR1 subunit displays a biphasic
\end{abstract}

decay, with a fraction of the protein having a half-life of only $1 \mathrm{~h}$ and the remaining presenting a turnover longer than $24 \mathrm{~h}$, similar to values obtained for the NR2A subunit. Our results also show a maturation process affecting the carbohydrate moiety in the NR1 subunit, such that immature NR1 has a much shorter halflife than the mature form or the NR2A subunit. Finally, we show that only a fraction of mature NR1 interacts with NR2A to form multimeric functional complexes.

Key words: maturation, stability, vaccinia virus.

\section{INTRODUCTION}

The $N$-methyl-D-aspartate (NMDA) receptors, a distinct subgroup of ionotropic glutamate receptors, are multimeric proteins in the membrane of postsynaptic densities that have key roles in neuronal plasticity and neurotoxicity in the central nervous system $[1,2]$. Binding of glutamate and the co-agonist glycine, together with depolarization of the membrane, causes activation of the intrinsic $\mathrm{Ca}^{2+}$ channel of the receptor [3]. Functional NMDA receptors in mammals are heteromeric proteins, with NR1 being an obligatory subunit interacting with a second class of subunits consisting of proteins NR2A-NR2D, which are thought to confer functional variability on the receptor [4-7]. Equivalent regions in NR1 and NR2 subunits contribute to coagonist binding sites: NR1 forms the glycine-binding site $[8,9]$, whereas NR2 contains the glutamate-binding site [10].

To understand the physiology of NMDA receptors, a thorough analysis of the mechanisms modulating the expression of the different subunits, and the role that they have in channel assembly and function, is required. Multiple levels of regulation have been described, including developmental and regional control [11,12] and regulation in individual synapses [13-15]. Whereas both mRNA [6] and protein NR1 [16] have a widespread but distinct distribution in neurons of the rat brain, developmental and regional expression of NR2 subunits is more finely regulated $[11,12,17]$. In addition, the trafficking of NR 1 and NR2A subunits is different: only $40-50 \%$ of total NR1 immunoreactivity is found at the cell surface in cultured hippocampal neurons, whereas more than $90 \%$ is obtained for NR2B [18]. The existence of two separate pools of NR1 subunits in cultured cerebellar granule cells [19] and in mammalian forebrain has been suggested
[20]. One of them might correspond to protein assembled to NR2A in plasma membrane, slowly degraded with a half-life similar to NR2A; the other, comprising most of the intracellular NR1 protein, would be rapidly degraded. This pool of NR1 might constitute a reserve for rapid association with co-assembling subunits when their synthesis is increased [19].

The stoichiometry of native NMDA receptors in the plasma membrane is not yet known; both tetrameric [21,22] and pentameric models have been proposed [23]. The regulatory mechanisms ensuring that only the appropriate complexes are targeted to the plasma membrane are also not yet known, although exit from the endoplasmic reticulum (ER) is likely to be an important checkpoint. In addition, the ER is required for the appropriate folding, glycosylation and disulphide bond formation of proteins in the secretory pathway. To prevent misfolded proteins from moving along this pathway, efficient quality control systems have evolved in metazoans [24,25]. For multimeric proteins, additional quality control standards must also be met to ensure a correct quaternary structure. However, the temporal relationship between protein synthesis, folding, modification and oligomerization in the ER is not always the same because it is an intrinsic property of proteins in the secretory pathway and not a consequence of the cellular environment (reviewed in [26]). Several models have been proposed to explain the sorting of multimeric proteins out of the ER (reviewed in [27]). One model postulates that only some combinations of assembled subunits can achieve correct folding, and unassembled or misassembled ones are retained in the ER by chaperones that recognize unfolded proteins [28]. Another possibility is that monomers contain discrete ER retention signals that are hidden or overcome by forward trafficking signals in a correctly assembled channel [29]. Eventu-

Abbreviations used: DL-AP5, 2-aminophosphonopentanoic acid; ER, endoplasmic reticulum; NHS-SS-biotin, sulphosuccinimidyl-2-(biotinamido)ethyl-1,3-dithiopropionate; NMDA, N-methyl-D-aspartate; VV, vaccinia virus.

To whom correspondence should be addressed (e-mail jrenart@iib.uam.es). 
ally, defective proteins might be translocated from the ER to the cytosol in a highly selective process, in which ubiquitin-conjugating enzymes target them for proteasome degradation [30,31], a process often known as ER-associated degradation ('ERAD') (reviewed in [32]).

The contribution of the different subunits in the assembly, maturation and function of multimeric complexes has been solved in many cases by the use of heterologous expression systems. With this approach, changes in the stability and/or subcellular localization of particular subunits of multimeric complexes have been observed when they are expressed by themselves as opposed to situations in which all subunits are expressed. For example, subunit $\mathrm{GABA}_{\mathrm{B}} \mathrm{R} 1$ expressed alone in HEK-293 cells is retained as an immature glycoprotein in intracellular membranes, whereas co-expression with $\mathrm{GABA}_{\mathrm{B}} \mathrm{R} 2$ produces a functional $\mathrm{GABA}_{\mathrm{B}}$ receptor at the cell surface [33]. In voltage-gated $\mathrm{K}^{+}$channels, the $\mathrm{N}$-glycosylation, stability and cell surface expression of $\alpha \mathrm{Kv} 1.2$ subunits are increased by auxiliary $\beta$ subunits [34].

We have previously established an efficient heterologous system of expression of NMDA receptors by using HEK-293 cells that produce NR1 and NR2A subunits with the help of vaccinia virus (VV) [35]. We have shown that the functioning of these receptors is extremely sensitive to inhibition of $\mathrm{N}$-glycosylation, mainly due to the retention of non-glycosylated NR1 and NR2A subunits in the ER and the fast and specific degradation of NR1 protein. The same response has been observed in rat cortical neurons, in which degradation of nonglycosylated NR1 is triggered by the ER stress response (M. García-Gallo, J. Renart and M. Díaz-Guerra, unpublished work). Here we report the analysis of the stability, maturation, assembly and transport to the plasma membrane of the receptor subunits by comparing cells producing NR1 or NR2A alone to cells expressing both subunits together.

\section{MATERIALS AND METHODS}

\section{Chemicals}

The NMDA receptor antagonist 2-aminophosphonopentanoic acid (DL-AP5) was from Tocris-Cookson (Bristol, Avon, U.K.). N-glycosidase F was from Roche Molecular Biochemical (Mannheim, Germany). Sulphosuccinimidyl-2-(biotinamido)ethyl-1,3dithiopropionate (EZ-Link NHS-SS-biotin) and bicinchoninic acid reagent were from Pierce (Rockford, IL, U.S.A.). Streptavidin-CL-4B agarose was from Fluka and Protein ASepharose was from Sigma (St Louis, MO, U.S.A.). All other products were of the highest quality available.

\section{Cell culture}

HEK-293 cells (ATCC CRL 1573) were grown in DMEM (Dulbecco's modified Eagle's medium) containing 10\% (v/v) fetal bovine serum, $40 \mu \mathrm{g} / \mathrm{ml}$ gentamicin and $2 \mathrm{mM}$ glutamine. African green monkey kidney cells (BSC-40) were grown as before but with newborn calf serum. Cells were grown at $37^{\circ} \mathrm{C}$ in air $/ \mathrm{CO}_{2}(19: 1)$. VV was always manipulated in the $\mathrm{P} 2$ facility of the Instituto de Investigaciones Biomédicas.

\section{Plasmids and viruses}

Plasmids coding for NR1-1a splice variant (pNR1) [6] and the NR2A subunit of the rat NMDA receptor ( $\mathrm{pNR} 2 \mathrm{~A}$ ) [7] were supplied by Dr S. Nakanishi. Both plasmids contain the coding sequence in pBlueScript (Stratagene, La Jolla, CA, U.S.A.) under the control of the bacteriophage T7 promoter. The recombinant virus vTF7-3 [36], expressing the T7 RNA polymerase gene under the control of the VV early/late promoter p7.5, was provided by Dr J. Ortín (CNB, CSIC, Madrid, Spain). This virus was grown and titrated in BSC-40 cells with standard procedures [37].

\section{Expression of the NMDA receptor}

HEK-293 cells $\left(3 \times 10^{6}\right.$, in six-well plates) were infected for $1 \mathrm{~h}$ with vTF7-3 at a multiplicity of 4 plaque-forming units per cell at $37^{\circ} \mathrm{C}$. After adsorption, the virus inoculum was removed, cells were washed once with DMEM without serum and transfected with Transfectace liposomes as described [35]. Transfection of NR1 and NR2A genes was performed with $4 \mu \mathrm{g}$ of plasmids pNR1 and pNR2A; single transfections were performed with $4 \mu \mathrm{g}$ of one of those plasmids plus $4 \mu \mathrm{g}$ of pBlueScript $\mathrm{SK}(-)$. Control transfections were made with $8 \mu \mathrm{g}$ of pBlueScript SK $(-)$ alone. Lipids and DNA were incubated for $15 \mathrm{~min}$ in DMEM without serum and then added to the infected cells for 5-6 h. Then DMEM with $10 \%$ (v/v) serum and $2 \mathrm{mM}$ DL-AP5 was added; cells were incubated for up to $24 \mathrm{~h}$ after infection.

\section{Subcellular fractionation}

HEK-293 cells grown in P100 plates were infected/transfected as before but with a total of $40 \mu \mathrm{g}$ of DNA. After $24 \mathrm{~h}$, medium was removed and cells were scraped in $2.5 \mathrm{ml}$ of ice-cold PBS. Plates were rinsed with $2.5 \mathrm{ml}$ of PBS and the cell suspension was centrifuged for $1 \mathrm{~min}$ at $5200 \mathrm{~g}$. Pellets were resuspended in $1 \mathrm{ml}$ of buffer A [300 mM sucrose $/ 100 \mathrm{mM}$ Tris $/ \mathrm{HCl}(\mathrm{pH} 7.4) / 1 \mathrm{mM}$ EDTA/0.5 mM dithiothreitol] containing protease inhibitors ( $1 \mathrm{mM}$ PMSF, $10 \mu \mathrm{g} / \mathrm{ml}$ leupeptin, $10 \mu \mathrm{g} / \mathrm{ml}$ aprotinin and $10 \mathrm{mM}$ benzamidine). After Dounce homogenization, cell suspension was centrifuged at $1000 \mathrm{~g}$ for $1 \mathrm{~min}$ at $4{ }^{\circ} \mathrm{C}$. Supernatants were then centrifuged at $100000 \mathrm{~g}$ for $45 \mathrm{~min}$ at $4{ }^{\circ} \mathrm{C}$ and the pellets obtained were resuspended in $1 \mathrm{ml}$ of buffer B (buffer A without sucrose). After another centrifugation step under the same conditions, the sediment contained cellular membranes. The protein concentration in each sample was determined with the bicinchoninic acid reagent and equivalent amounts of protein were subjected to SDS/PAGE and Western blotting with specific antibodies.

\section{Biotinylation of cell-surface proteins}

HEK-293 cells were infected and transfected as before. At $24 \mathrm{~h}$ after infection, medium was collected and cells were washed four times with HBSS (Hanks balanced salt solution) containing $25 \mathrm{mM} \mathrm{KCl}, 1.26 \mathrm{mM} \mathrm{CaCl}, 0.5 \mathrm{mM} \mathrm{MgCl}_{2}$ and $0.4 \mathrm{mM}$ $\mathrm{MgSO}_{4}$. Surface proteins were then biotinylated for $30 \mathrm{~min}$ in HBSS containing NHS-SS-biotin $(1 \mathrm{mg} / \mathrm{ml})$ at $4{ }^{\circ} \mathrm{C}$, essentially as described [19]. Cells were washed four times with HBSS and incubated in conditioned medium for $15 \mathrm{~min}$ at $37^{\circ} \mathrm{C}$. Cells were then washed again with HBSS before being harvested in RIPA buffer $\left[10 \mathrm{mM} \mathrm{Na} \mathrm{HPO}_{4}(\mathrm{pH} 7.2) / 150 \mathrm{mM} \mathrm{NaCl} / 1 \%\right.$ (w/v) deoxycholate $/ 1 \%(\mathrm{v} / \mathrm{v})$ Nonidet $\mathrm{P} 40 / 0.1 \%$ SDS] containing protease inhibitors. Protein extracts were incubated with streptavidin-CL-4B agarose to precipitate biotinylated proteins. Pellets were solubilized in sample buffer and subjected to SDS/PAGE and Western blot analysis.

\section{Metabolic labelling}

Cells were starved in DMEM lacking both methionine and cysteine (Biowhittaker) for $3 \mathrm{~h}$ in the presence of $2 \mathrm{mM}$ DL-AP5 
and were pulsed for $30 \mathrm{~min}$ with $150 \mu \mathrm{Ci} / \mathrm{ml}$ Pro-Mix L- $\left[{ }^{35} \mathrm{~S}\right]$ $\left(70 \%\right.$ [ ${ }^{35}$ S]methionine $/ 30 \%\left[{ }^{35}\right.$ S $]$ cysteine; Amersham Pharmacia). They were then washed with cold PBS before lysis for 30 min at $4{ }^{\circ} \mathrm{C}$ in buffer L $[1 \%(\mathrm{v} / \mathrm{v}) \mathrm{NP} 40 / 20 \mathrm{mM}$ Tris $/ \mathrm{HCl}$ (pH 8)/80 mM NaCl/20 mM EDTA] containing protease inhibitors. For pulse-chase analysis, cells were labelled as described above. After pulse, unlabelled methionine was added to the medium to a final concentration of $30 \mathrm{mg} / \mathrm{ml}$. Cells were then washed twice with DMEM containing $3 \mathrm{mg} / \mathrm{ml}$ methionine before incubation for variable durations in growth medium, always in the presence of $2 \mathrm{mM}$ DL-AP5. At the indicated times cells were lysed as described above.

\section{Immunoprecipitation}

Before immunoprecipitation, cell extracts were diluted with 1 vol. of buffer L without detergent. Approximately $200 \mu \mathrm{g}$ of protein were incubated with the following amounts of specific antibodies : $2.5 \mu \mathrm{g}$ of mouse monoclonal anti-NR1 (PharMingen, San Diego, CA, U.S.A.) and $5 \mu \mathrm{g}$ of rabbit polyclonal antiNR2A/B (Chemicon, Temecula, CA, U.S.A.). After $1 \mathrm{~h}$ at $4{ }^{\circ} \mathrm{C}$, immunocomplexes were precipitated with $100 \mu \mathrm{l}$ of $10 \%$ Protein A-Sepharose, also for $1 \mathrm{~h}$ at the same temperature. Beads were washed four times with the buffer used for immunoprecipitation, before solubilization in sample buffer.

\section{Quantification of pulse-chase experiments}

Autoradiograms were quantified by densitometric scanning with the NIH Image v1.6 program. The quantity of subunit remaining at each time point was expressed as a percentage of the protein precipitated from pulse-labelled cells.

\section{Immunocytochemistry}

HEK-293 cells were grown on coverslips and infected/transfected as described previously. At $24 \mathrm{~h}$ after infection, cells were washed with PBS and fixed for $15 \mathrm{~min}$ at room temperature with $3.7 \%$ (v/v) formaldehyde in PBS plus $4 \%(w / v)$ sucrose [38]. After being washed with PBS, cells were permeabilized for $5 \mathrm{~min}$ at room temperature with $0.25 \%$ (v/v) Triton X-100 in PBS and then blocked for $1 \mathrm{~h}$ at $37^{\circ} \mathrm{C}$ in PBS plus $1 \%(\mathrm{w} / \mathrm{v})$ gelatin. The same conditions were used for incubation with anti-NR1 $(1: 100)$, anti-NR2A/B (1:50) or both antibodies. Rabbit anti-NR2A/B antibodies were pre-adsorbed for $30 \mathrm{~min}$ at $4{ }^{\circ} \mathrm{C}$ on a dry acetone precipitate obtained from HEK-293 cells infected/transfected with the NR1 gene as described [35]. Coverslips were washed four times (10 min each) with PBS and incubated as before with 1:100 dilution of goat anti-rabbit antibodies labelled with rhodamine (Jackson Laboratories, Bar Harbor, ME, U.S.A.) or goat anti-mouse antibodies labelled with 4,4-difluoro-4-bora3a,4a-diaza-s-indacene (BODIPY ${ }^{\text {(M) }}$ ) (Molecular Probes, Eugene, OR, U.S.A.). After four additional washes with PBS, coverslips were mounted with Mowioll. Cells were photographed with a Zeiss Axiophot fluorescence microscope.

\section{Other methods}

Treatment with $\mathrm{N}$-glycosidase $\mathrm{F}$ was performed on immunoprecipitated proteins resuspended in $30 \mu \mathrm{l}$ of $50 \mathrm{mM}$ sodium phosphate (pH 7.2)/20 mM EDTA/0.1\% (v/v) 2-mercaptoethanol $/ 0.8 \%$ (v/v) Triton X-100/0.4\% SDS. Incubation proceeded for $14 \mathrm{~h}$ at $37^{\circ} \mathrm{C}$ with 20 units $/ \mathrm{ml}$ enzyme as described in [39]. PAGE and the immunodetection of proteins transferred to Immobilon-P membranes (Millipore) were performed by standard procedures with the antibodies mentioned above $(0.25 \mu \mathrm{g} / \mathrm{ml}$ anti-NR1 and $0.5 \mu \mathrm{g} / \mathrm{ml}$ anti-NR2A) or a rabbit polyclonal anti-VV serum [40] kindly supplied by Dr M. Esteban (CNB, CSIC). Goat secondary antibodies coupled to horseradish peroxidase were from ICN Biomedicals. Immunocomplexes were detected with the enhanced chemiluminescence $\left(E C L^{\mathbb{B}}\right)$ kit from Amersham, in accordance with the manufacturer's instructions.

\section{RESULTS}

\section{Subcellular localization of NMDA receptor subunits expressed alone}

In the heterologous system we developed previously, the expression of functional NMDA receptors is obtained by the transfection of genes encoding subunits NR1 and NR2A, under the control of T7 RNA polymerase promoter, in HEK-293 cells infected with the recombinant VV vTF7-3, which produces the bacteriophage RNA polymerase [35]. By using immunofluorescence we were able to demonstrate the co-localization of NR1 and NR2A subunits in the plasma membrane of doubly transfected cells, although protein was also detected in the cytoplasm. To analyse the contribution of each receptor subunit to the subcellular localization described above, we decided to identify where the NR1 and NR2A proteins are located when expressed alone. Infected/transfected cells were left to produce the subunits for $24 \mathrm{~h}$ in the presence of DL-AP5, a competitive inhibitor of the NMDA receptor. Immunocytochemistry of permeabilized cells transfected with the NR1 gene alone showed a pattern of staining (Figure 1c) indistinguishable from that obtained in cells expressing this protein together with the NR2A subunit (Figure 1a). In contrast, cells transfected with the NR2A gene alone showed a pattern of staining with the NR2A antibody different from that obtained in cells expressing both subunits (compare Figures 1f and 1b). The NR2A subunit was still visible in the cytoplasm of those cells but there was no staining of the plasma membrane. In every case the pattern of staining of cells that were positive for a specific antibody was similar: all cells transfected with the NR1 gene alone showed membrane staining, whereas no cells containing NR2A had this pattern.

To improve the characterization of the cellular location of the NMDA receptor subunits, we performed a subcellular fractionation of extracts prepared from infected/transfected cells. Figure 2(A) shows the result of immunoblot analysis of these samples with NR1- and NR2A-specific antibodies. The receptor subunits were found exclusively in the $100000 \mathrm{~g}$ sediment, corresponding to membrane fractions (Figure 2A, lanes 2, 4 and 6 ), whereas neither NR1 nor NR2A was detected in the soluble fraction (Figure 2A, lanes 1, 3 and 5). It is noteworthy that these results were independent of whether the subunits were coexpressed or produced separately. From this experiment we conclude that the NR1 and NR2A subunits are associated with cell membranes independently of single or double transfection of the genes encoding the receptor subunits.

To detect differential localization in cell membranes, we performed cell-surface biotinylation, a specific assay for proteins exposed in the cell surface [41]. Infected/transfected cells were labelled with biotin for $30 \mathrm{~min}$ at $4{ }^{\circ} \mathrm{C}$ as indicated, or left untreated as a control, followed by the isolation of biotinylated proteins with streptavidin. In cells transfected with the NR 1 gene alone, the NR1 protein was specifically sedimented by streptavidin-agarose in cells labelled with biotin but not in unlabelled cells (Figure 2B, middle panel, lanes 2 and 4). There is therefore cell-surface localization of NR1 even in the absence of NR2A; moreover, the amount of this subunit found in the plasma membrane is of the same order as that in cells expressing 


\section{anti NR1}
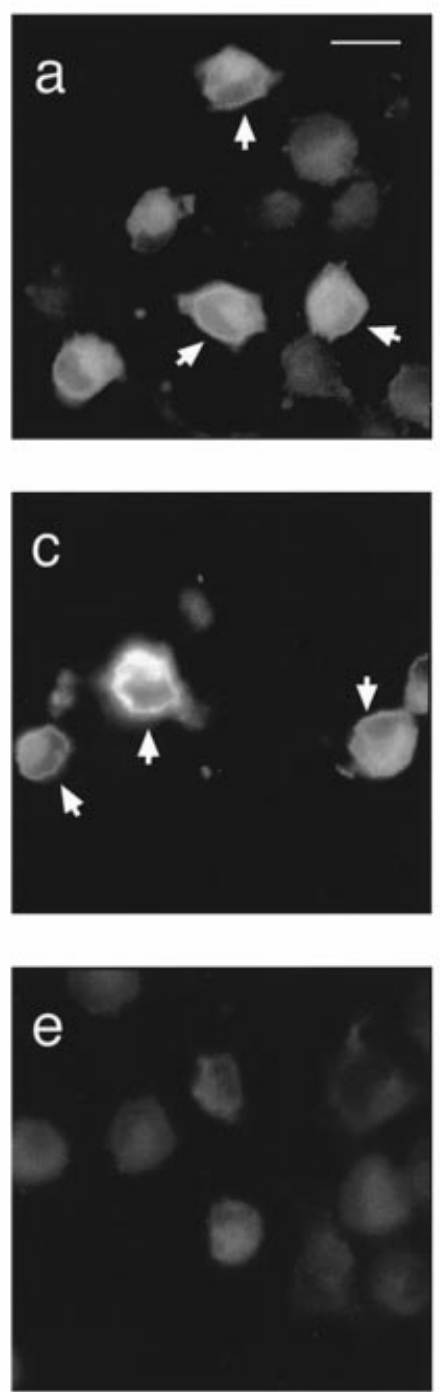

anti NR2A
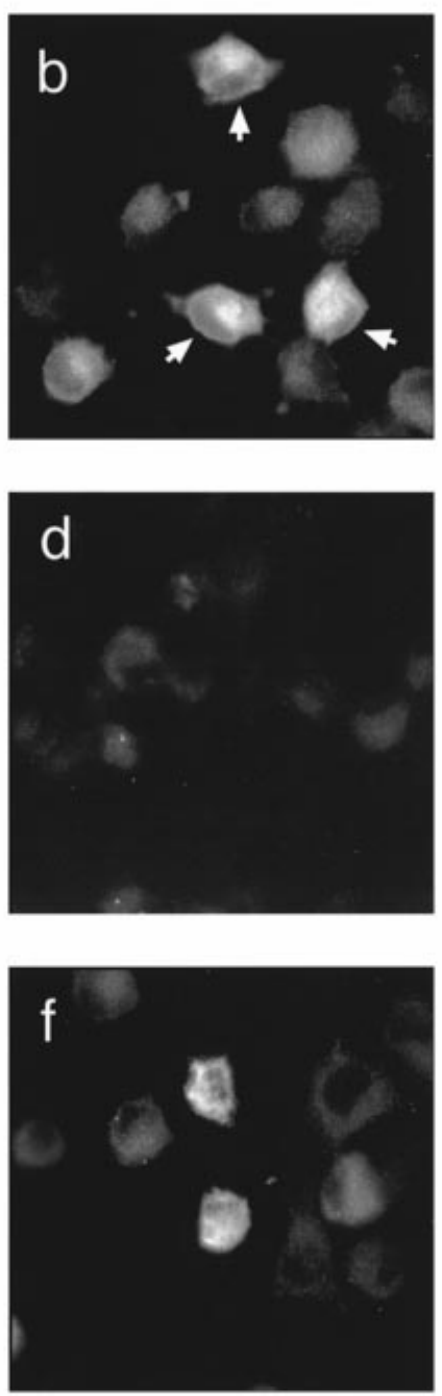

pNR1

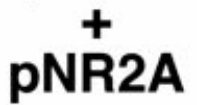

pNR1

PNR2A

Figure 1 Immunocytochemistry of cells expressing NMDA receptor subunits

HEK-293 cells grown on coverslips were infected as described in the Materials and methods section and transfected with NR1 and NR2A genes (a, b), NR1 genes (c, d) or NR2A genes (e, f). After $24 \mathrm{~h}$ in the presence of $2 \mathrm{mM} \mathrm{DL-AP5}$, cells were fixed and permeabilized as described and incubated with antibodies against NR1 (a, c, e) or NR2A subunits (b, d, $\mathbf{f})$. Samples were observed with a fluorescence microscope with a $63 \times$ oil-immersion objective and photographed. Arrows point to regions of plasma membrane staining. Scale bar, $16 \mu \mathrm{m}$.

this subunit together with NR2A (Figure 2B, middle panel, compare lanes 4 and 12). We therefore conclude that NR1 transport to the cell surface does not require interaction with the NR2A subunit and has a comparable efficiency in both situations. In contrast, NR2A was not labelled in cells transfected only with this gene (Figure 2B, top panel, lane 8), whereas biotinylated protein was sedimented by streptavidin-agarose in cells transfected with NR1 and NR2A genes (Figure 2B, top panel, lane 12). This result indicates that NR2A cannot be transported to the cell surface by itself and requires previous interaction with the NR1 receptor subunit. The specificity of biotin labelling for cellsurface proteins is shown in Figure 2(B) (bottom panel), in which we used a polyclonal antiserum against VV [40] that recognizes several early and late viral proteins in total extracts produced in the heterologous system (Figure 2B, bottom panel, odd-numbered lanes). Only one of the proteins recognized by this antiserum was sedimented by the streptavidin-agarose complex in biotinylated cells (Figure 2B, bottom panel, lanes 4, 8 and 12) but not in control experiments without biotin (lanes 2, 6 and 10), excluding the possibility of non-specific labelling of intracellular proteins.

From Figures 1 and 2 we conclude that the NMDA receptor subunits are always associated with cell membranes: NR1 is found in the plasma membrane whether NR2A is co-expressed or not, whereas NR2A is found associated with the plasma membrane only in the presence of NR1.

\section{Analysis of the stability of NMDA receptor subunits expressed alone and in cells producing NR1 and NR2A}

Because proteins that are normally found as hetero-oligomeric complexes can have altered stability when expressed alone, we 
A

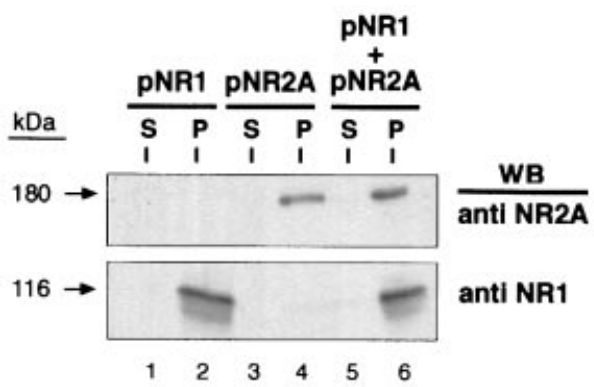

B

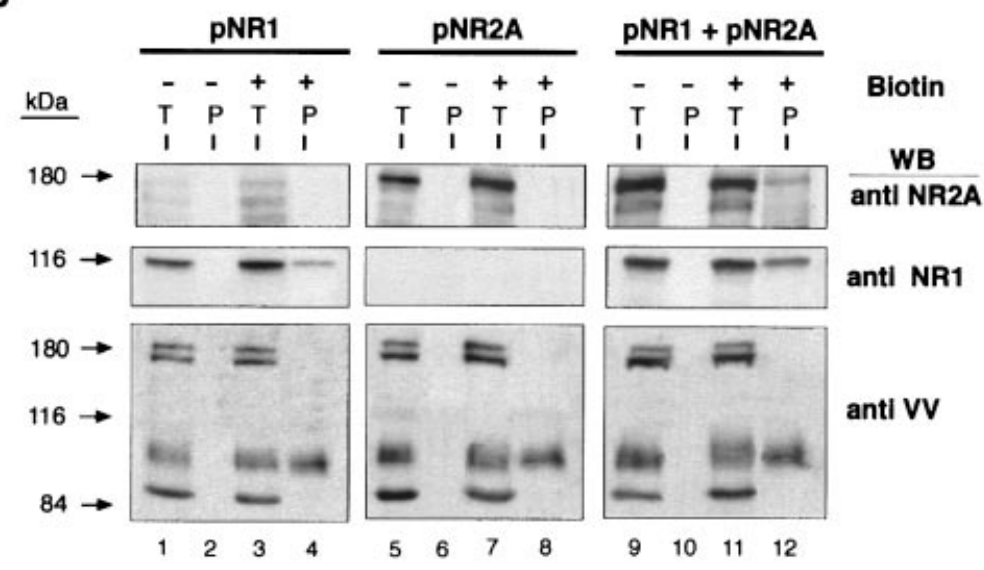

Figure 2 Subcellular localization of NMDA receptor subunits

(A) Subcellular fractionation. Infected cells were transfected with plasmids pNR1 (lanes 1 and 2), pNR2A (lanes 3 and 4) or pNR1 and pNR2A (lanes 5 and 6). Infections proceeded for 24 h in the presence of $2 \mathrm{mM} \mathrm{DL-AP5}$; cells were then collected and processed as described. Abbreviations: P, sediment obtained at $100000 \boldsymbol{g}$; S, soluble fraction. After electrophoresis, Western blot (WB) analysis was performed with antibodies specific for NR2A (upper panel) or NR1 subunits (lower panel). (B) Labelling of cell-surface proteins. Cells infected/transfected with plasmids pNR1 (lanes 1-4), pNR2A (lanes 5-8) or pNR1 + pNR2A (lanes 9-12) were labelled with biotin for 30 min (lanes 3, 4, 7, 8, 11 and 12) or left untreated (lanes 1, 2, 5, 6, 9 and 10) as described previously. Proteins sedimented with streptavidin-agarose (P) or total extracts (T) were analysed by Western blotting with antibodies specific for NR2A (top panel) or NR1 (middle panel) or with anti-VV serum (bottom panel).

decided to compare the half-lives of NR1 and NR2A expressed alone and together. For pulse-chase experiments, infected/ transfected cells were treated as described in the Materials and methods section. After a $30 \mathrm{~min}$ pulse, proteins were chased for 0-24 h and immunoprecipitated (Figure 3). As a control, we also pulse-labelled cells transfected with pBlueScript (SK - ) plasmid (Figure 3, lanes 1). The turnovers of NR1 and NR2A subunits were different (Figure 3D). For NR2A, although some synthesis de novo was observed at the beginning of the chase time, the estimated half-life was longer than $24 \mathrm{~h}$. For NR1 we found two phases in the degradative process: turnover was very fast for the first $30 \mathrm{~min}$, with only $70 \%$ of labelled protein remaining after this time; the decay in the second phase was much slower. The half-life of the rapidly degrading pool of NR1 protein was $1 \mathrm{~h}$ but that of the slowly degrading subunit was longer than $24 \mathrm{~h}$, similar to that of the NR2A subunit. However, we did not observe any difference between the half-lives of proteins NR1 (Figure 3A) and NR2A (Figure 3B) whether they were expressed alone or together (Figure 3C), demonstrating that interaction between the receptor subunits is not a factor determining protein stability in this case. In conclusion, our results suggest the existence of two different pools of NR1 subunits identified by their differential stability, which can be seen in cells producing this subunit either alone or together with the NR2A protein. In equivalent situations, only a slowly degrading pool of NR2A protein was detected.

\section{Characterization of the maturation process of NR1}

In the pulse-chase experiments in Figure 3, we detected a change in the electrophoretic mobility of protein NR1 in up to $2 \mathrm{~h}$ of chase duration (Figure 3A, and Figure 3C, lower panel, lanes 2-4) that was not observed for NR2A (Figure 3B, and Figure 3C, upper panel). To test whether this difference might be due to a maturation process of the carbohydrate moiety in NR1, immunoprecipitated polypeptides in Figure $3(\mathrm{C})$ were treated in vitro with $\mathrm{N}$-glycosidase $\mathrm{F}$, which specifically eliminates carbohydrates in Asn residues, producing completely deglycosylated proteins. Figure 4 shows the result of this experiment. As expected, the sizes of the proteins NR1 and NR2A after treatment with the glycosidase (lanes 2-7) were smaller than those in untreated samples (lanes 8 and 9) and were coincident with the molecular mass of non-glycosylated proteins, 97 and $165 \mathrm{kDa}$ respectively for deglycosylated NR1 (dgNR1) or NR2A (dgNR2A). In addition, the mobility of dgNR 1 protein (Figure 4, lower panel, lanes 2-7) was the same for the different chasing durations, demonstrating that NR1 was undergoing a maturation process affecting the carbohydrate residues present in this glycoprotein. 
A
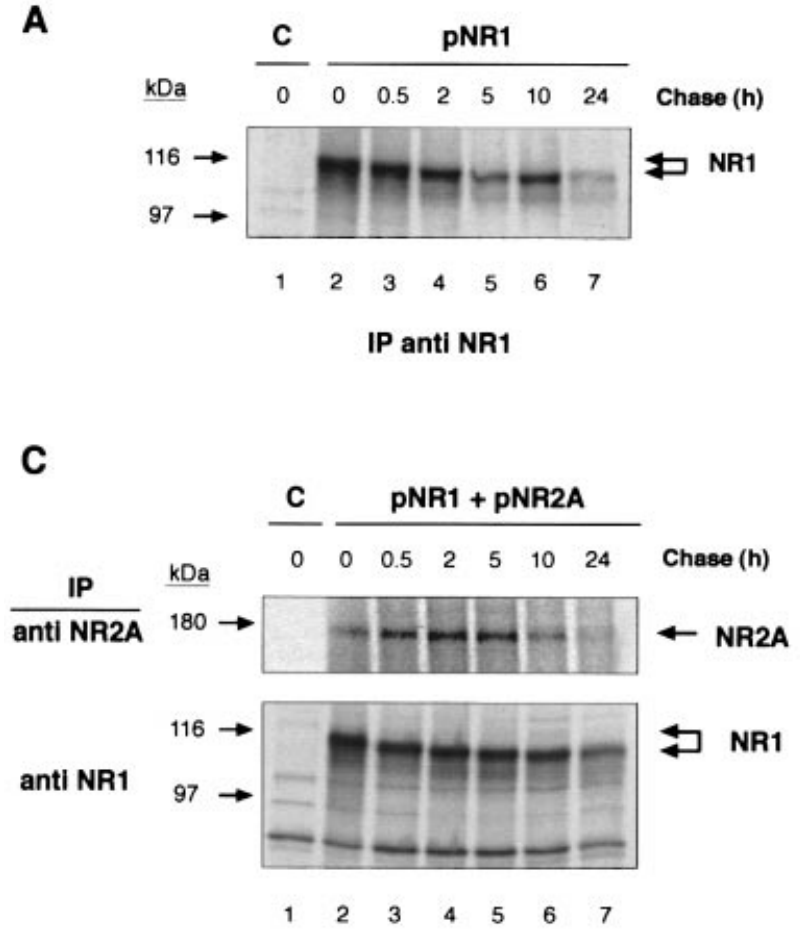

B
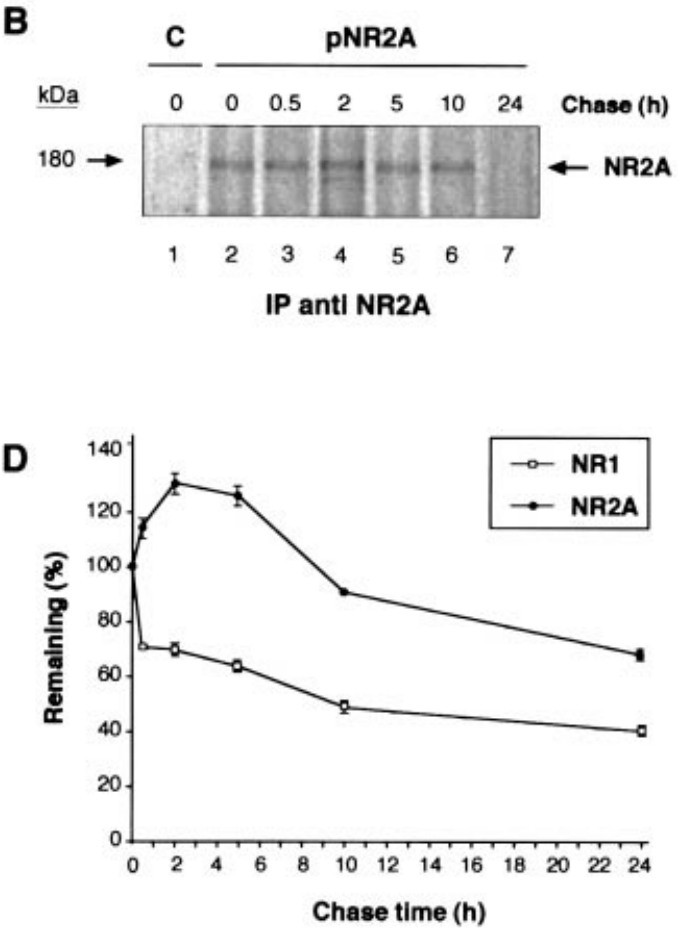

Figure 3 Analysis of the stability of NMDA receptor subunits

Infected cells were transfected with plasmids pNR1 (A), pNR2A (B) or pNR1 and pNR2A (C), or pBlueScript SK( - ) as a control (lanes 1$)$. After 24 h, cells were labelled for 30 min as described in the Materials and methods section. Cells were collected immediately (lanes 1 and 2) or changed to normal medium for the indicated chase durations (lanes $3-7)$. Protein extracts were immunoprecipitated (IP) with antibodies specific for NR1 (A; C, lower panel) or NR2A subunits (B; C, upper panel) and proteins detected by autoradiography. (D) Densitometric analysis of the relative stability of NMDA receptor subunits in cells expressing both proteins: $\square$, NR1; $\boldsymbol{O}$, NR2A. Autoradiograms were quantified by densitometric scanning. The quantity of subunits remaining at each time point was expressed as a percentage of the protein precipitated from pulse-labelled cells. Bars represent the results of two independent experiments.

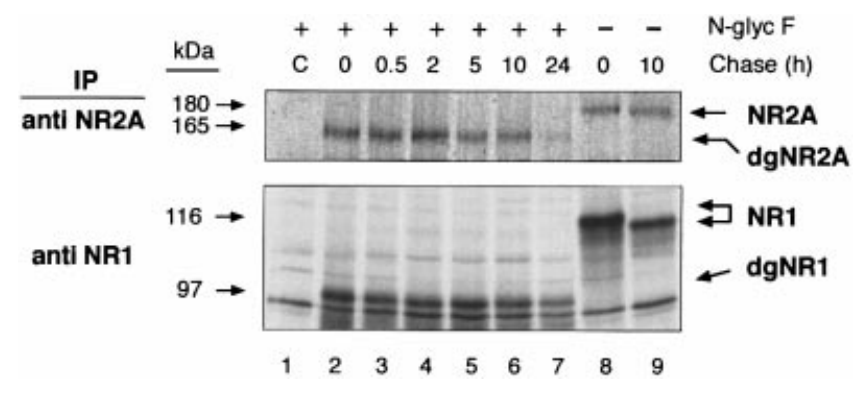

Figure 4 Analysis of NR1 subunit maturation

Proteins immunoprecipitated (IP) with specific antibodies (experiment in Figure 3C) were treated in vitro with $\mathrm{N}$-glycosidase $\mathrm{F}$ as indicated and analysed by autoradiography (lanes 1-7). Untreated samples corresponding to chasing times of 0 and $10 \mathrm{~h}$ in Figure $3(\mathrm{C})$ are also included (lanes 8 and 9).

\section{Analysis of the differential expression and assembly of NR1 and NR2A subunits}

We have noticed in this and previous work that the amount of NR1 detected by immunoassays was always considerably higher than that observed for the NR2A subunit. To exclude the possibility that the differences were due only to a differential affinity of the antibodies used, we compared levels of NR1 and NR2A subunits synthesized de novo in a $30 \mathrm{~min}\left[{ }^{35} \mathrm{~S}\right] \mathrm{methionine/}$ $\left[{ }^{35} \mathrm{~S}\right]$ cysteine pulse, followed by electrophoresis of total extracts and autoradiography of dried gels (Figure 5A). Cells were infected/transfected with plasmids $\mathrm{pNR} 1$ and $\mathrm{pNR} 2 \mathrm{~A}$ or a control plasmid. Expression of recombinant proteins mediated by VV/T7-polymerase is highly efficient [36] and, additionally, the detection of heterologous proteins is facilitated by shut-off of cellular proteins as a consequence of infection [42]. It was therefore possible to observe two bands corresponding to NR1 and NR2A (Figure 5A, lane 2) that were not present in control samples (Figure 5A, lane 1) and could be immunoprecipitated by specific antibodies (results not shown). Because the percentage of Met + Cys residues is the same for both proteins $(4.5 \%)$, we interpret this result as meaning that the levels of NR1 subunit synthesized de novo are considerably higher that those of NR2A.

Previous results [35] and results presented here demonstrate that the NR1 and NR2A subunits produced in doubly transfected cells co-localize in membrane structures, including the plasma membrane. Because these proteins form a functional receptor, the NR1 and NR2A subunits should be able to co-immunoprecipitate. We therefore lysed infected/transfected cells under conditions in which protein interactions were maintained; extracts were immunoprecipitated and proteins in the precipitates were detected by immunoblotting with the same antibodies (Figure 5B). As predicted, protein NR1 immunoprecipitated with its specific antibody (Figure $5 \mathrm{~B}$, lower panel, lane 1) carried subunit NR2A (Figure 5B, upper panel, lane 1). Similarly, immunoprecipitates of protein NR2A (Figure 5B, upper panel, lane 2) also contained NR1 (Figure 5B, lower panel, lane 2). These results therefore confirm the interaction between proteins NR1 and NR2A produced in this heterologous system. In this 
A

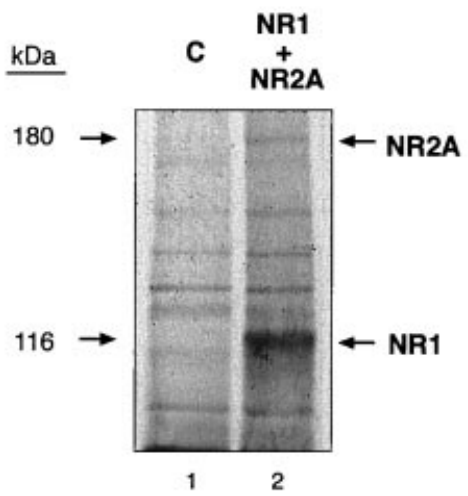

B

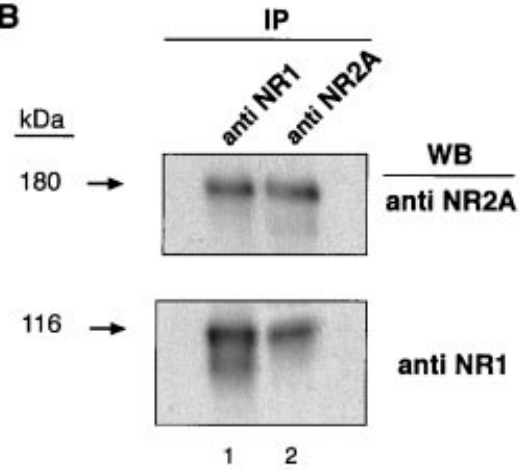

Figure 5 Differential expression of NMDA receptor subunits

(A) Infected cells were transfected with plasmids pNR1 and pNR2A (lane 2), or pBlueScript SK $(-)$ as a control (lane 1). After $24 \mathrm{~h}$ in the presence of $2 \mathrm{mM}$ DL-AP5, cells were pulselabelled for 30 min with $\left[{ }^{35} \mathrm{~S}\right]$ methionine/ $\left[{ }^{35} \mathrm{~S}\right]$ cysteine as before. Cells were then collected and total extracts were analysed by gel electrophoresis and autoradiography. (B) Extracts from HEK293 cells infected/transfected with plasmids pNR1 and pNR2A were subjected to immunoprecipitation (IP) with antiserum against NR1 (lane 1) or NR2A (lane 2) subunits. Precipitated proteins were analysed by immunoblotting (WB) with the indicated antibodies.

experiment it was also evident that the amount of NR1 subunit involved in interactions with NR2A was only a fraction of total protein (Figure 5B, lower panel, compare lanes 1 and 2), whereas the amounts of NR2A precipitated with its specific antibody or the NR1 antibody were comparable (Figure 5B, upper panel, compare lanes 1 and 2). In conclusion, only a fraction of the NR1 protein produced in the cell is assembled with NR2A subunits and there is an important pool of the protein not involved in this kind of interaction.

We next tried to analyse whether the interaction between NR1 and NR2A subunits was dependent on NR1 maturation, by performing co-immunoprecipitation assays of proteins labelled in a pulse-chase experiment and comparing the results with those obtained by direct immunoprecipitation of the same proteins (Figure 6). The results corresponding to NR1 precipitated by interaction with NR2A (Figure 6B, lower panel) were different from those obtained by direct immunoprecipitation of the same extracts (Figure 6A, lower panel). First, the electrophoretic mobility of the NR1 protein associated with NR2A did not change during the chasing times analysed and corresponded to the mature form of the protein. Secondly, the amount of coimmunoprecipitated NR1 increased to a maximum at $2 \mathrm{~h}$ of chase (Figure 6B, lower panel, lane 4), the time estimated for NR1 to complete maturation. Thereafter we observed a slow decay (Figure 6B, lower panel, lanes 5-7). Although difficult to
A

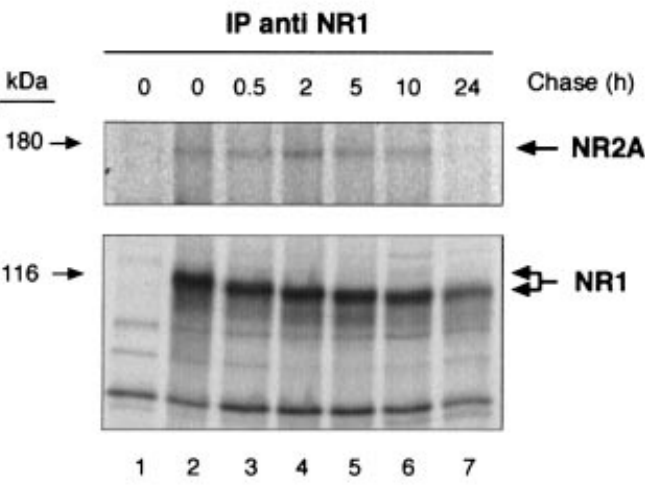

B

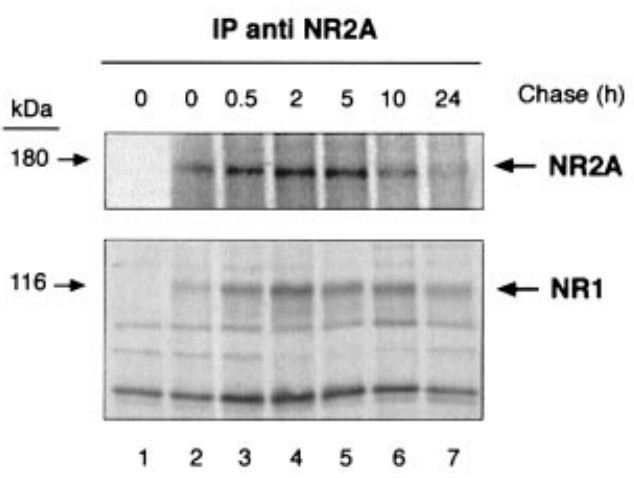

Figure 6 Analysis by co-immunoprecipitation of the assembly of NMDA receptor subunits

Cells infected/transfected with plasmids pNR1 and pNR2A were subjected to immunoprecipitation with antiserum against NR1 $(\mathbf{A})$ or NR2A $(\mathbf{B})$ subunits. Precipitated proteins were analysed by gel electrophoresis and autoradiography. The upper panel in (A) shows coimmunoprecipitation of NR2A subunit by NR1-specific antiserum; the lower panel in (B) shows protein NR1 sedimented by NR2A antibodies. To facilitate the comparison, results of direct immunoprecipitation shown in Figure 3(C) are also included.

assert, the kinetics of the NR2A subunit associated with NR1 (Figure 6A, upper panel) might be similar to that of NR1. We therefore conclude that assembly of the heteromeric complex requires the previous maturation of the carbohydrate moiety of the NR1 protein.

\section{DISCUSSION}

The results presented here address different aspects of NMDA receptor biogenesis of great relevance to an understanding of the physiology of these important neuronal channels. Although results obtained with recombinant receptors must be interpreted with caution, the use of heterologous systems of expression permits an approach to questions on the contribution of the different subunits to receptor assembly and function, which are difficult to study in natural systems. Here we have used a highly efficient expression system based on the use of $\mathrm{VV}$, which is able to produce functional receptors that sustain $\mathrm{Ca}^{2+}$ influxes and delayed toxicity dependent on receptor agonists and inhibited by receptor antagonists [35]. As expected, cells transfected with NR1 and NR2A genes express the subunits in the cell surface as demonstrated by immunofluorescence and biotinylation assays (Figures 1 and 2). Interestingly, when the receptor subunits are expressed separately, we observe a differential response: NR1 is 
transported to the plasma membrane alone with an efficiency comparable to that of cells producing both subunits, whereas NR2A requires NR1 co-expression to be displayed in the cell surface and when expressed alone remains associated with intracellular membranes (Figures 1 and 2). However, the amounts of receptor subunits that accumulate after single or double transfection of cells are approximately the same (Figure 2B, oddnumbered lanes), a result justified by the observation that the stability of these proteins does not change when expressed alone or together (Figure 3). Changes have previously been shown in the stability and/or localization of subunits of hetero-oligomeric complexes when expressed alone [33,34]; here we found only a modification in the transport of the NR2A receptor subunit, whereas the stability seemed to be an intrinsic property of the proteins. Present models propose that some proteins expose ER retention signals (as with secretory immunoglobulins) (reviewed in [26]) or degradation sequences (as with some subunits in the Tcell receptor) [43] that are abolished by protein maturation through a conformational change or by masking of the signal by interaction with other subunits in the complex. It will be interesting to find the signals in the NR2A sequence that are responsible for retention of this protein when the NR1 subunit is not present.

Several lines of evidence demonstrate the existence of two separate pools of NR1 protein. First, in pulse-chase experiments we observe biphasic kinetics of NR1 decay (Figure 3). An important part of this protein has a half-life of $1 \mathrm{~h}$, whereas the turnover for the rest is slow and comparable to that of the NR2A subunit (more than $24 \mathrm{~h}$ ). Secondly, we have unveiled for the first time a maturation process affecting the carbohydrate moiety of the NR1 subunit (Figure 4). NR1 synthesized de novo has an electrophoretic mobility notably lower than that of protein chased after $2 \mathrm{~h}$ with unlabelled medium or of protein detected by immunoblotting. We have not observed a similar process for the NR2A subunit, although we cannot exclude this possibility completely. Thirdly, in terms of interaction with NR2A, there are also two different pools: only the form of NR1 with high electrophoretic mobility can establish interactions with NR2A (Figure 6); the immature form, which correlates with the pool of protein of high turnover, remains unassembled. We therefore propose that the maturation of carbohydrate residues in NR1 is a limiting step for NMDA receptor oligomerization and that an important fraction of the NR1 subunit, unable to complete this maturation process, is rapidly degraded. Results presented here for the heterologous system are in agreement with previous observations published for neuronal systems. In cerebellar granule cells in culture, Huh and Wenthold [19] also observed two separate pools of NR1 of very different stability. The slowly degraded NR1 corresponded to protein in the cell surface, probably associated with NR2A, whereas most of the intracellular protein was rapidly degraded. However, they proposed that the only difference between the two pools of NR1 was the establishment of an interaction with NR2A, implying that NR1 required this interaction to be driven to the cell surface. Our results showing that NR1 is able to reach the plasma membrane independently of NR2A expression are difficult to reconcile with this hypothesis. We believe that a different biochemical property might be characterizing the two pools of NR1. Although not observed by these authors, it will be interesting to analyse whether NR1, a protein with a high mannose or hybrid content [19], suffers a maturation process in neurons similar to that observed here, limiting the formation of multimeric complexes.

The transport to the cell surface of mammalian cells of NMDA receptor subunits expressed alone has been studied in several heterologous systems with somewhat contradictory results
[44-48]. By using immunofluorescence, COS-7 cells transiently transfected with rat NR1-1a subunit (the splice variant form used in this work) [45] or a stable cell line producing human NR1 [44] express this protein in the plasma membrane. In contrast, other reports $[46,47]$ showed that in permanently transfected mouse L cells, or transiently transfected COS and HEK-293 cells, neither NR1 nor NR2A alone was expressed at the cell surface but formed large intracellular accumulations in the ER. Okabe et al. [48] have found a differential cell surface expression of NR1 splice variants produced alone in fibroblasts: no surface staining was observed in cells expressing NR1-1a and NR1-1b; for the other splice variants, a variable percentage $(4.0-35 \%)$ of the cells that were stained with antibodies presented the signal in the plasma membrane. We have no clear explanation for this discrepancy with our results; not only have we found expression of NR1-1a at the plasma membrane but the pattern of staining among the producing cells is homogeneous, in the sense that all positive cells for the subunit express it at the membrane.

Another important observation of the present study is that synthesis of NR1 protein de novo is notably increased over NR2A expression (Figure 5A) and, although the stability of the former is lower, the steady-state levels of NR1 observed in immunoblots and immunoprecipitation assays are always higher than those of the NR2A subunit. These observations suggest that only a fraction of the mature NR1 protein interacts with the NR2A subunit (Figure 5B). Significant differences in the amount of subunits produced have also been observed in heterologous systems [49] and in hippocampal neurons in culture [18], in which an important intracellular pool of NR1 subunit has also been observed. Because transcription of NR1 and NR2A is driven by the same promoter in the heterologous system used here, the reason for the increased synthesis of NR1 de novo might be a greater stability of the mRNA coding this subunit or a more efficient translation of this mRNA.

At present we do not know the oligomeric state of NR1 in the plasma membrane when expressed alone. Other authors have considered the possibility that this protein is able to form homomers in heterologous systems $[44,49,50]$. It will be very interesting to investigate the multimeric state of protein NR1 expressed with our heterologous system. If it is found in homomeric structures in the plasma membrane, it might be possible that there are also homo-oligomeric complexes of NR1 of as yet unknown function in neurons.

We thank Dr S. Nakanishi for the gift of the receptor subunits plasmids, Dr Mariano Esteban for serum against VV, and Carmen Moratilla for technical help. This work was supported by grants from Comisión Interministerial de Ciencia y Tecnología (SAF97-0136) and Comunidad Autónoma de Madrid (08.9/0005/1998), Spain.

\section{REFERENCES}

1 Choi, D. W. (1995) Calcium: still center-stage in hypoxic-ischemic neuronal death. Trends Neurosci. 18, 58-60

2 Bliss, T. V. and Collingridge, G. L. (1993) A synaptic model of memory: Iong-term potentiation in the hippocampus. Nature (London) 361, 31-39

3 Mori, H. and Mishina, M. (1995) Review: Neurotransmitter receptors VIII: structure and function of the NMDA receptor channel. Neuropharmacology 34, 1219-1237

4 Monyer, H., Sprengel, R., Schoepfer, R., Herb, A., Higuchi, M., Lomeli, H., Burnashev, N., Sakmann, B. and Seeburg, P. H. (1992) Heteromeric NMDA receptors: molecular and functional distinction of subtypes. Science 256, 1217-1221

5 Meguro, H., Mori, H., Araki, K., Kushiya, E., Kutsuwada, T., Yamazaki, M., Kumanishi, T., Arakawa, M., Sakimura, K. and Mishina, M. (1992) Functional characterization of a heteromeric NMDA receptor channel expressed from cloned cDNAs. Nature (London) 357, 70-74

6 Moriyoshi, K., Masu, M., Ishii, T., Shigemoto, R., Mizuno, M. and Nakanishi, S. (1991) Molecular cloning and characterization of the rat NMDA receptor. Nature (London) 354, 31-37 
7 Ishii, T., Moriyoshi, K., Sugihara, H., Sakurada, K., Kadotani, H., Yokoi, M., Akazawa, C., Shigemoto, R., Mizuno, N., Masu, M. and Nakanishi, S. (1993) Molecular characterization of the family of the $\mathrm{N}$-methyl-D-aspartate receptor subunits. J. Biol. Chem. 268, 2836-2843

8 Kuryatov, A., Laube, B., Betz, H. and Kuhse, J. (1994) Mutational analysis of the glycine-binding site of the NMDA receptor: structural similarity with bacterial amino acid-binding proteins. Neuron 12, 1291-1300

9 Hirai, H., Kirsch, J., Laube, B., Betz, H. and Kushe, J. (1996) The glycine binding site of the $\mathrm{N}$-methyl-D-aspartate receptor subunit NR1: identification of novel determinants of coagonist potentiation in the extracellular M3-M4 loop region. Proc. Natl. Acad. Sci. U.S.A. 93, 6031-6036

10 Laube, B., Hirai, H., Sturgess, M., Betz, H. and Kuhse, J. (1997) Molecular determinants of agonist discrimination by NMDA receptor subunits: analysis of the glutamate binding site on the NR2B subunit. Neuron 18, 493-503

11 Monyer, H., Burnashev, N., Laurie, D. J., Sakmann, B. and Seeburg, P. H. (1994) Developmental and regional expression in the rat brain and functional properties of four NMDA receptors. Neuron 12, 529-540

12 Ikeda, K., Nagasawa, M., Mori, H., Araki, K., Sakimura, K., Watanabe, M., Inoue, Y. and Mishina, M. (1992) Cloning and expression of the epsilon 4 subunit of the NMDA receptor channel. FEBS Lett. 313, 34-38

13 Landsend, A. S., Amiry-Moghaddam, M., Matsubara, A., Bergersen, L., Usami, S., Wenthold, R. J. and Ottersen, O. P. (1997) Differential localization of delta glutamate receptors in the rat cerebellum: coexpression with AMPA receptors in parallel fiberspine synapses and absence from climbing fiber-spine synapses. J. Neurosci. 17, 834-842

14 Rubio, M. E. and Wenthold, R. J. (1997) Glutamate receptors are selectively targeted to postsynaptic sites in neurons. Neuron 18, 939-950

15 Zhao, H. M., Wenthold, R. J., Wang, Y. X. and Petralia, R. S. (1997) Delta-glutamate receptors are differentially distributed at parallel and climbing fiber synapses on Purkinje cells. J. Neurochem. 68, 1041-1052

16 Brose, N., Gasic, G. P., Vetter, D. E., Sullivan, J. M. and Heinemann, S. F. (1993) Protein chemical characterization and immunocytochemical localization of the NMDA receptor subunit NMDA R1. J. Biol. Chem. 268, 22663-22671

17 Petralia, R. S., Wang, Y. X. and Wenthold, R. J. (1994) The NMDA receptor subunits NR2A and NR2B show histological and ultrastructural localization patterns similar to those of NR1. J. Neurosci. 14, 6102-6120

18 Hall, R. A. and Soderling, T. R. (1997) Differential surface expression and phosphorylation of the $\mathrm{N}$-methyl-D-aspartate receptor subunits NR1 and NR2 in cultured hippocampal neurons. J. Biol. Chem. 272, 4135-4140

19 Huh, K.-H. and Wenthold, R. J. (1999) Turnover analysis of glutamate receptors identifies a rapidly degraded pool of the $N$-methyl-D-aspartate receptor subunit, NR1 in cultured cerebellar granule cells. J. Biol. Chem. 274, 151-157

20 Chazot, P. L. and Stephenson, F. A. (1997) Biochemical evidence for the existence of a pool of unassembled C2 exon-containing NR1 subunits of the mammalian forebrain NMDA receptor. J. Neurochem. 68, 507-516

21 Laube, B., Kushe, J. and Betz, H. (1998) Evidence for a tetrameric structure of recombinant NMDA receptors. J. Neurosci. 18, 2954-2961

22 Rosenmund, C., Stern-Bach, Y. and Stevens, C. F. (1998) The tetrameric structure of a glutamate receptor channel. Science 280, 1596-1599

23 Hawkins, L. M., Chazot, P. L. and Stephenson, F. A. (1999) Biochemical evidence for the co-association of three $\mathrm{N}$-methyl-D-aspartate (NMDA) R2 subunits in recombinant NMDA receptors. J. Biol. Chem. 274, 27211-27218

24 Gething, M. J. and Sambrook, J. (1992) Protein folding in the cell. Nature (London) 355, 33-45

25 Kopito, R. R. (1997) ER quality control: the cytoplasmic connection. Cell 88, 427-430

26 Reddy, P. S. and Corley, R. B. (1998) Assembly, sorting, and exit of oligomeric proteins from the endoplasmic reticulum. BioEssays 20,546-554

27 Hendershot, L. M. (2000) Giving protein traffic the green light. Nat. Cell Biol. 2 , E105-E106

28 Kowalski, J. M., Parekh, R. N., Mao, J. and Wittrup, K. D. (1998) Protein folding stability can determine the efficiency of escape from endoplasmic reticulum quality control. J. Biol. Chem. 273, 19453-19458
29 Klausner, R. D., Lippincott-Schwartz, J. and Bonifacino, J. S. (1990) The T cell antigen receptor: insights into organelle biology. Annu. Rev. Cell Biol. 6, 403-431

30 Brodsky, J. L. and McCracken, A. A. (1999) ER protein quality control and proteasome-mediated protein degradation. Semin. Cell Dev. Biol. 10, 507-513

31 Werner, E. D., Brodsky, J. L. and McCracken, A. A. (1996) Proteasome-dependent endoplasmic reticulum-associated protein degradation: an unconventional route to a familiar fate. Proc. Natl. Acad. Sci. U.S.A. 93, 13797-13801

32 Bonifacino, J. S. and Weissman, A. M. (1998) Ubiquitin and the control of protein fate in the secretory and endocytic pathways. Annu. Rev. Cell Dev. Biol. 14, 19-57

33 White, J. H., Wise, A., Main, M. J., Green, A., Fraser, N. J., Disney, G. H., Barnes, A. A., Emson, P., Foord, S. M. and Marshall, F. H. (1998) Heterodimerization is required for the formation of a funtional $\mathrm{GABA}_{\mathrm{B}}$ receptor. Nature (London) $\mathbf{3 9 6}$, 679-682

34 Shi, G., Nakahira, K., Hammond, S., Rhodes, K. J., Schechter, L. E. and Trimmer, J. S. (1996) $\beta$ subunits promote $\mathrm{K}^{+}$channel surface expression through effects early in biosynthesis. Neuron 16, 843-852

35 García-Gallo, M., Behrens, M. M., Renart, J. and Díaz-Guerra, M. (1999) Expression of $\mathrm{N}$-methyl-D-aspartate receptors using vaccinia virus causes excitotoxic death in human kidney cells. J. Cell. Biochem. 72, 135-144

36 Fuerst, T. R., Earl, P. L. and Moss, B. (1987) Use of a hybrid vaccinia virus-T7 RNA polymerase system for expression of target genes. Mol. Cell. Biol. 7, 2538-2544

37 Earl, P. L., Cooper, N. and Moss, B. (1991) Preparation of cell cultures and vaccinia virus stocks. In Current Protocols in Molecular Biology (Ausubel, F. M., Brent, R., Kingston, R. E., Moore, D. D., Seidman, J. G., Smith, J. A. and Struhl, K., eds.), pp. 16.16.1-16.16.7, Green Publishing Associates/Wiley Interscience, New York

38 Ehlers, M. D., Tingley, W. G. and Huganir, R. L. (1995) Regulated subcellular distribution of the NR1 subunit of the NMDA receptor. Science 269, 1734-1737

39 Cik, M., Chazot, P. L. and Stephenson, F. A. (1993) Optimal expression of cloned NMDAR1/NMDAR2A heteromeric glutamate receptors: a biochemical characterization. Biochem. J. 296, 877-883

40 Demkowicz, W. E., Maa, J. S. and Esteban, M. (1992) Identification and characterization of vaccinia virus genes encoding proteins that are highly antigenic in animals and are immunodominant in vaccinated humans. J. Virol. 66, 386-398

41 Altin, J. G. and Pagler, E. B. (1995) A one-step procedure for biotinylation and chemical cross-linking of lymphocyte surface and intracellular membrane-associated molecules. Anal. Biochem. 224, 382-389

42 Esteban, M. and Metz, D. H. (1973) Early virus protein synthesis in vaccinia virusinfected cells. J. Gen. Virol. 19, 201-206

43 Bonifacino, J. S., Cosson, P. and Klausner, R. D. (1990) Colocalized transmembrane determinants for ER degradation and subunit assembly explain the intracellular fate of TCR chains. Cell 63, 503-513

44 Grimwood, S., Le Bourdelles, B. and Whiting, P. J. (1995) Recombinant human NMDA homomeric NR1 receptors expressed in mammalian cells form a high-affinity glycine antagonist binding site. J. Neurochem. 64, 525-530

45 Ishmael, J. E., Franklin, P. H., Murray, T. F. and Leid, M. (1996) High level expression of the NMDAR1 glutamate receptor subunit in electroporated COS cells. J. Neurochem. 67, 1500-1510

46 Mcllhinney, R. A., Molnar, E., Atack, J. R. and Whiting, P. J. (1996) Cell surface expression of the human $\mathrm{N}$-methyl-D-aspartate receptor subunit 1a requires the $\mathrm{co-}$ expression of the NR2A subunit in transfected cells. Neuroscience 70, 989-997

47 Mcllhinney, R. A., Le Bourdelles, B., Molnar, E., Tricaud, N., Streit, P. and Whiting, P. J. (1998) Assembly intracellular targeting and cell surface expression of the human N-methyl-D-aspartate receptor subunits NR1a and NR2A in transfected cells. Neuropharmacol. 37, 1355-1367

48 Okabe, S., Miwa, A. and Okado, H. (1999) Alternative splicing of the C-terminal domain regulates cell surface expression of the NMDA receptor NR1 subunit. J. Neurosci. 19, 7781-7792

49 Grimwood, S., Le Bourdellès, B., Atack, J. R., Barton, C., Cockett, W., Cook, S. M., Gilbert, E., Hutson, P. H., McKernan, R. M., Myers, J. et al. (1996) Generation and characterization of stable cell lines expressing recombinant human $\mathrm{N}$-methyl-Daspartate receptor subtypes. J. Neurochem. 66, 2239-2247

50 Chazot, P. L., Cik, M. and Stephenson, F. A. (1992) Immunological detection of the NMDAR1 glutamate receptor subunit expressed in human embryonic kidney 293 cells and in rat brain. J. Neurochem. 59, 1176-1178

Received 8 November 2000/2 March 2001; accepted 22 March 2001 